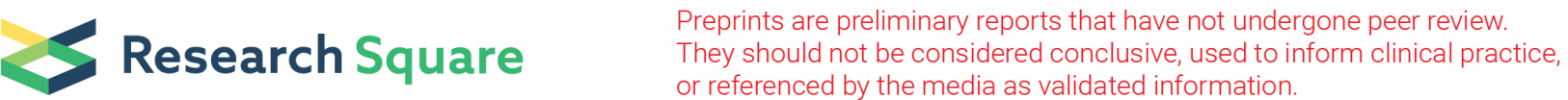

\section{Psychosocial Distress and Exposure to Sexually Explicit Materials as Correlates of Sexual Intercourse among Adolescents in Dodoma- Tanzania}

Abdalla Hussein ( $\square$ abdallahussein49@yahoo.com )

University of Dododma https://orcid.org/0000-0002-4651-4555

Abbas Ismail

The University of Dodoma College of Natural Sciences and Mathematics

Augustine Malero

The University of Dodoma College of Informatics and Virtual Education

Habibu Dadi

The University of Dodoma College of Education

James Charles

Dodoma Regional Hospital

Mery Sando

Africa Academy for Public Health

Wafaei Fawzi

Harvard University T H Chan School of Public Health

\section{Said Vuai}

The University of Dodoma College of Natural Sciences and Mathematics

Research article

Keywords: Adolescent sexuality, sexual intercourse, psychosocial distress, sexually explicit materials, Dodoma HDSS

Posted Date: July 8th, 2020

DOl: https://doi.org/10.21203/rs.3.rs-39477/v1

License: (1) This work is licensed under a Creative Commons Attribution 4.0 International License. Read Full License 


\section{Abstract}

Background: Adolescents' sexuality is topical in public health discussions owing to its ability to increase the risk of HIV infection and other sexually transmitted diseases. Research shows that adolescents' sexual behavior, psychosocial distress, and exposure to sexually explicit material(SEM) are interconnected in that they need collective health interventions for adolescents. Although mental health factors, such as psychological distress, are common in developing and middle-income countries, including Tanzania, these factors are less considered in HIV research. Thus, there is a need to raise awareness on the role of mental health factors in HIV epidemic. This study is, therefore, a response to this requirement by examining the contribution of psychosocial distress and exposure to sexually explicit materials on sexual intercourse among adolescents in Dodoma Region of Tanzania.

Methods: A cross-sectional survey was conducted in five villages of Chamwino District from April to June 2017 among 1,226 adolescents of 10-19 years' age. A stratified random sampling technique was used to select the respondents. A weighted logistic regression model was used to examine the independent contribution of psychosocial distress and exposure to sexually explicit materials on sexual intercourse while accounting for study design.

Results: The overall lifetime prevalence of adolescent sexuality was $20.38 \%$. The prevalence was observed to be higher among males $(32.15 \%)$ as compared to females $(10.92 \%)$. Adolescent sexuality was significantly associated with both psychosocial distress and exposure to sexually explicit materials. The odds ratios showed that adolescents reported psychosocially distressed (AOR=1.61, $95 \% \mathrm{Cl}$ : 1.321.96) and those exposed to sexually explicit materials ( $A O R=4.26,95 \% \mathrm{Cl}: 3.65-4.97)$ were at higher risk of having sexual intercourse. Other variables associated with sexual intercourse were age, sex, alcohol use, and current schooling status.

Conclusion: The analysis made through this study came to the conclusion that as HIV risk continues to be a serious concern among adolescents, adolescent sexuality, psychosocial distress, and exposure to sexually explicit materials are interconnected. This calls for upfront interventions on school health education and services, particularly on the ventures to lower psychosocial distress and avert exposure on sexually explicit materials to prevent the spread of HIV and other sexually transmitted diseases.

\section{Background}

In East Africa, HIV and AIDS are major and historical public health problems. In 2016, 1.4 million people were HIV positive in Tanzania. This is estimated to 4.7\% prevalence of HIV positive adults[1]. The 2017 Tanzania HIV Impact Survey (THIS) revealed that one percent of Tanzanian female adolescents age 1519 years are HIV-positive[2].

In Africa, a large extent of HIV transmission is through heterosexual intercourse[3]. Sexual intercourse by younger adolescents is connected to risky outcomes. Some of these include multiple partners, unintended pregnancy, pelvic inflammatory disease, HIV, and other sexually transmitted diseases [4-8]. Research in 
Kenya shows that there is a positive association between early sexual initiation and HIV infection[9]. Another study conducted in Kenya among school-going adolescents in Coast Province reported that $14.9 \%$ of them involved in sexual intercourse in the past 12 months[3]. In Brazil, Sasaki et al. [10] reported that $26.5 \%$ of the student adolescents in Goiania in the state of Goias had had sexual intercourse. A survey conducted in Ethiopia, among Jimma Teacher Training College Students aged 15-29 years, revealed that the overall prevalence of pre-marital sexual intercourse was $39.7 \%(63.4 \%$ in males and $36.6 \%$ in females)[11]. According to 2017 Tanzania Mainland, Global School-based Student Health Survey (GSHS) report, overall, $20.0 \%$ of students aged $13-17$ years had sexual intercourse in their life, among whom $76.5 \%$ started before age 14 years, and $5.3 \%$ had sexual intercourse with two or more partners during their life. Among the students who had had sexual intercourse, only $36.5 \%$ used a condom, and $33.1 \%$ used other methods of birth control during the last sexual intercourse[12].

Today, adolescents grow up in a society where they are easily exposed to sexually explicit material (SEM) [13]. It is also claimed that adolescents have access to abundant information via escalating technologies [14-16]. While there is increased access to information, parents and professionals have been less concerned about children's exposure to sexually explicit material and their impacts. Research suggests that adolescent exposure to such content is linked with shifts in attitudes about sex and hence affects adolescent sexual performance orientation[17, 18]. Besides, research shows that users may learn from SEM to engage in sexual interactions. They may learn these through observation and hearings about a variety of sexual behaviors[19]. Yet, there is little evidence regarding the influence of adolescent involvement in SEM and their sexual behavior hence the proposed study is felt important at this juncture.

Further, psychological distress depression, and anxiety have also been found to have a huge impact on adolescent engagement in sexual behaviors[20, 21]. To illustrate, a department of Health Science, Brigham Young University (2009) conducted by psychosocial distress and the use of as factors for adolescent sexual behavior in sub-Saharan African. The sample of this study consisted of 22,949 adolescents from Kenya, Zambia, Botswana, Namibia, Uganda, and Zimbabwe who were involved in 2003 or 2004 GSHS surveys. Multiple sexual partners were associated with both psychosocial distress and the use of alcohol [22]. This suggests that adolescent sexual behavior is associated with the availability of distress. The limitation of this is that the study had little focus on the Tanzania context. This prompts the need to have a study that would examine the association of psychological distress and adolescent sexual behavior in the Tanzania context. Therefore, the current study sought to examine the contribution of psychosocial distress and exposure to sexually explicit materials on sexual intercourse among adolescents in Dodoma-Tanzania.

\section{Methods}

\section{Data sources}

The data of the adolescent study of Dodoma Health and Demographic Surveillance System (HDSS) were used for the current study. Dodoma HDSS is a longitudinal study that was developed by the University of 
Dodoma (UDOM) in collaboration with Africa Academy for Public Health (AAPH), the Harvard T. H. Chan School of Public Health, and the Dodoma Regional Health Management Team with the intent of providing information on longitudinal data regarding socio-demographic and health of the individuals.

\section{Study design and set up of the Dodoma Adolescent Study}

A community-based cross-sectional study among adolescents was done in Dodoma rural at Chamwino District from April to June 2017. The District has a total population of 330,543 individuals of which 71,208 are adolescents [23]. The survey was nested within the platform of the HDSS site in Chamwino, Dodoma. The site involved two wards with a total of five villages. The HDSS site has registered 5256 households with a population of 23785 and adolescents aged 10-19 years are 6162. The adolescent survey included adolescents aged 10-19 years.

\section{Sample Size And Sampling Technique}

The current study adopted the sample size and sampling procedures of the Dodoma adolescents study. The sample size was obtained through the Cochran formula holding these assumptions: $50 \%$ prevalence (p) of malnutrition, $5 \%$ desired precision and adolescent population $(\mathrm{N})$ of 6162 individuals. Based on the given information, a minimum sample size required was 362 adolescents. To avoid non-response that could occur during data collection, an adjusted sample size of 517 respondents was calculated by using assuming a minimum response rate of $70 \%$. However, the sample size was collected beyond the expectation and the final sample size obtained was 1,226 adolescents. The respondents of the study were selected from a stratified sample of the adolescent population of Dodoma HDSS. The SAS PROC SURVEY SELECT procedure was employed to select the sample while villages were the sampling strata.

\section{Survey Administration And Instrumentation}

Dodoma adolescents' study used a standardized structured questionnaire across seven countries.

The questionnaire was amended in tablets and administered in electronic form. The questionnaire

included variables of socio-economy, socio-demography, food security, teeth and hand wash, food diversity, feelings (mental health) and friendship, school, physical activity, and home activities, physical fighting, physical attacks, sexual practice, injuries, health status assessment, health care, life satisfaction, substance use, exposure to sexual explicit materials, pregnancy, media use, sexual transmitted infection, and nutrition status.

Open Health and Demographic Surveillance (Open HDS) data system was used to collect data. This uses android based tablets to enable the collection of data[24]. This web-based application allows research assistants to electronically register and collect information from households. The information is then 
linked to android based tablets through wireless synchronization and then sent to the central data store based on the Open Data Kit (ODK) [24, 25].

\section{Measures}

The current study mainly focused on 3 of the questionnaire-units of the Dodoma adolescent survey namely sexual practice, mental health, and exposure to sexual explicit materials. The items from the questionnaire units are presented as follows:

\section{Sexual Practice}

This module consisted of four items: "Have you ever had sexual intercourse?"," For the first time you had sexual intercourse, how old were you?" "The last time you had sexual intercourse, did you or your partner use a condom?" and ", with how many people have you had sexual intercourse during your life time?" To assess the magnitude of sexual contact, which is the outcome variable for this study, a dichotomous answer to item one "Have you ever had sexual intercourse" was used. The response options were $1=$ yes and $2=$ no. The response was then recoded as $1=$ yes and $0=$ no.

\section{Psychosocial Distress}

Psychosocial distress was measured across 4 mental health indicators of distress: anxiety or worried, loneliness, sadness, and attempt to suicide. The items options were as follows:

Loneliness: "During the past four months, how often have you felt lonely?" (The options were: 1 = never, 2 $=$ rarely, $3=$ sometimes, $4=$ most of the time, and $5=$ Always). The response were recoded as $1=$ most of the time or always and $0=$ never, rarely, or sometimes.

\section{Anxiety or Worried}

During the past four months, how often have you been so worried about something that you could not sleep at night? (Response options were $1=$ never, $2=$ rarely, $3=$ sometimes, $4=$ most of the time, and $5=$ Always.) (Coded $1=$ most of the time or always and $0=$ never, rarely or sometimes).

Sadness: Over the last week, how frequently have you experienced, depressed, low mood, sadness, and feeling blah or down, just couldn't be bothered? (Response option were: 1 = hardly ever, 2 = sometimes, 3 $=$ much of the time, $4=$ most of the time, to $5=$ all of the time.). The responses were recoded as $1=$ much of the time, most of the time or all of the time, $0=$ Hardly ever or sometimes.)

\section{Suicide attempt}


"Have you ever seriously consider attempting suicide during the last 12 months?" (Response option was $1=$ yes and $2=$ no, coded $1=1,2=0$ ).

The total frequency of psychosocial distress indicators was computed to determine if the respondent had $0,1,2$, and 3 or 4 indicators[22]. Subjects with 1 or more psychosocial distress indicators were considered to be psychosocially distressed.

\section{Exposure To Sexually Explicit Material}

This module included 5 items: "Have you ever watched a sexually explicit film?" "With whom do you usually watch sexually explicit films?", "How often did you watch such materials in the last month?", "where do you find the sexually explicit material you watched?" and "Have you ever sent /received a sexually suggestive text or picture?" The subject was considered to be exposed to sexually explicit material if he/she ever watched a sexually explicit film or ever sent or received a sexually suggestive text or picture.

\section{Data analysis}

All statistical analysis procedures were conducted using the SAS Version 9.4 software. To make statistics computed from the data more representative of the adolescents' population for each village in Dodoma HDSS, the sampling weights were used in data analysis. The sampling weights were computed as the inverse of selection probabilities. In the results, weighted percentages were reported. The contribution of psychosocial distress and sexually explicit materials on sexual intercourse, while adjusting for socialdemographic variables and alcohol use was evaluated using weighted multiple logistic regression models. The strength of association was construed through the adjusted odds ratio (AOR) and p-value. A bivariate weighted logistic regression model was first used for assessment of the crude impact of explanatory variables. All variables with $p$-values less or equal to 0.25 in bivariate analyses were counted in the multivariable models[26]. The criterion for statistical significance was set at a p-value of 0.05 .

\section{Results}

A description of the respondents of this study is accessible in Table 1. About $55 \%$ of the study participants were females and majority of them (i.e. 67\%) were adolescents aged 10-14 years. Six percent of the adolescents were alcohol users and almost $77 \%$ of the participants were students at the time of the study. A majority of the participants (i.e. 61.41\%) were living with both biological parents, $22 \%$ were victims of bullying and about $14 \%$ of the participants had psychosocial distress. 
Table 1

Percentage description of the respondents of the study

\begin{tabular}{|lll|}
\hline Variable & Frequency & Weighted Percent \\
\hline Age (Years) & & \\
\hline $10-14$ & 818 & 66.83 \\
\hline $15-19$ & 408 & 33.17 \\
\hline Sex & & \\
\hline Male & 548 & 44.55 \\
\hline Female & 678 & 55.45 \\
\hline Ever drink alcohol & & \\
\hline Yes & 76 & 5.77 \\
\hline No & 1150 & 94.23 \\
\hline Schooling status & & \\
\hline In school & 898 & 76.91 \\
\hline Out of school & 328 & 23.09 \\
\hline Family structure & & \\
\hline Both parents & 18046 & 81.41 \\
\hline Single Parent & 753 & 19.78 \\
\hline Others & 244.65 \\
\hline Bullying Victimization & 229 & 18.81 \\
\hline Yes & & \\
\hline No & & \\
\hline Psychosocial distress indicator & & \\
\hline Not distressed & & \\
\hline Distressed & & \\
\hline & & \\
\hline
\end{tabular}

\section{Adolescents' Exposure To Sexually Explicit Materials}

Reading through Table 1 , it is clear that a quarter $(28.30 \%)$ of the respondents was exposed to sexually explicit materials. Among the study participants, 324(26.47\%) had watched sexual explicit films and 57 $(4.80 \%)$ sent or received a sexually suggestive text or picture (Table 2 ). Among adolescents who watched 
sexual explicit films, a large majority (81.80\%) watched the films with friends of the same sex, and a tiny minority $(7.25 \%)$ watched them alone. Further, $19(6.02 \%)$ and $14(4.94 \%)$ watched the films with friends of the opposite-sex or someone else respectively. Among the adolescents who were exposed to sexually explicit films, $156(48.61 \%)$ of them had watched the films once or twice in the month before the survey while $58(16.76 \%)$ watched them thrice or more during the same period. The analysis showed that friends were the main information sources for sexually explicit films (64.09\%) followed by home of residence (16.52\%). 
Table 2

Adolescents Exposure to Sexually Explicit Materials

\begin{tabular}{|c|c|c|}
\hline Variable & frequency & Weighted percent \\
\hline \multicolumn{3}{|l|}{ Exposed to sexually explicit materials } \\
\hline Yes & 345 & 28.30 \\
\hline No & 881 & 71.70 \\
\hline Ever watch a sexually explicit film & $n=1226$ & \\
\hline Yes & 324 & 26.47 \\
\hline No & 902 & 73.53 \\
\hline With whom do you usually watch sexually explicit films? & $\mathrm{n}=324$ & \\
\hline Alone & 23 & 7.25 \\
\hline Same-sex friends & 268 & 81.80 \\
\hline Opposite sex friends & 19 & 6.02 \\
\hline Someone else & 14 & 4.94 \\
\hline How often did you watch such materials in the last one month & $n=324$ & \\
\hline 0 time & 110 & 34.63 \\
\hline $1-2$ times & 156 & 48.61 \\
\hline $3+$ times & 58 & 16.76 \\
\hline Where do you usually find the sexually explicit material you watch? & $\mathrm{n}=324$ & \\
\hline Internet & 5 & 1.71 \\
\hline Rental & 9 & 3.35 \\
\hline From a friend & 211 & 64.09 \\
\hline Found at home & 57 & 16.52 \\
\hline Others & 42 & 14.3245 \\
\hline Have you ever sent/received a sexually suggestive text or picture & $\mathrm{n}=324$ & \\
\hline Yes & 57 & 4.80 \\
\hline No & 1169 & 95.20 \\
\hline
\end{tabular}

\section{Adolescents Sexual Practice}


Overall, $20.38 \%$ of the adolescents had initiated sexual intercourse, with mean age at the first contact being 12.23 years. Among the adolescents who had had sexual contact, a majority (62\%) had their first sexual intercourse at the age of 12-19 years and $94(38 \%)$ had their first intercourse at less than 12 years. The proportion of subjects who initiated sexual intercourse at the age of less than 12 years was higher among males ( $47 \%$ ) compared to females ( $18 \%$ ). $47 \%$ of those who had sexual contacts had multiple sexual partners. The proportion of males' adolescents who had two or more sexual partners was higher $(58 \%)$ compared to females' counterparts (20\%). $72 \%$ of them reported not to use condoms for the last time they had sexual intercourse; the rate was higher among males $(76 \%)$ than females $(61 \%)$ (Table 3$)$.

Table 3

Percentage description of the study population by their sexual practice

\begin{tabular}{|c|c|c|c|}
\hline Variable & $\begin{array}{l}\text { Total } \\
\mathrm{n}(\%)\end{array}$ & $\begin{array}{l}\text { Male } \\
\mathrm{n}(\%)\end{array}$ & $\begin{array}{l}\text { Female } \\
\mathrm{n}(\%)\end{array}$ \\
\hline Ever had sexual intercourse & & $n=548$ & $n=678$ \\
\hline Yes & 259(20.38) & 179(32.15) & $80(10.92)$ \\
\hline No & $967(79.62)$ & $369(67.85)$ & $598(89.08)$ \\
\hline $\begin{array}{l}\text { Age had the first } \\
\text { sexual intercourse }\end{array}$ & $\mathrm{n}=259$ & $n=179$ & $\mathrm{n}=80$ \\
\hline$<=15$ & 192(76.98) & 150(85.68) & $42(17.54)$ \\
\hline $16-19$ & $67(23.02)$ & $29(14.32)$ & $38(82.46)$ \\
\hline Number of the sexual partner & $\mathrm{n}=259$ & $\mathrm{n}=179$ & $\mathrm{n}=80$ \\
\hline One & $141(53.16)$ & $76(41.67)$ & $65(80.32)$ \\
\hline Two or more & $118(46.84)$ & 103(58.33) & 15(19.68) \\
\hline $\begin{array}{l}\text { Did you or your partner use a condom the last time you } \\
\text { had sexual contact? }\end{array}$ & $\mathrm{n}=259$ & & \\
\hline Yes & $71(28.15)$ & $42(23.59)$ & $29(38.94)$ \\
\hline No & 188(71.85) & 137(76.41) & $51(61.06)$ \\
\hline
\end{tabular}

The distribution of sexual intercourse by psychosocial distress indicator exposed to sexually explicit materials and other demographic characteristics are presented in Table 4. The prevalence of sexual contact was high among adolescents, with psychosocial distress indicators (35\%) than none distressed counterparts (18\%). $46 \%$ of the adolescents exposed to sexually explicit material and $10 \%$ of those not exposed reported to had had sexual intercourse. There were more males than females $(32 \%$ and $11 \%$ respectively) who reported having had sexual intercourse at least once. $36 \%$ of the adolescents aged $15-$ 19 years and $12 \%$ of those aged $10-14$ years had engaged in sexual intercourse. The observed prevalence of sexual intercourse was higher among alcohol users (60\%) than non-users (18\%). Among 
the student adolescents, $12 \%$ reported having had sexual intercourse compared to $47 \%$ for those who were out of school. Further analysis revealed that the adolescent who had engaged in sexual intercourse had different family background: $19 \%$ of them lived with biological parents, $22 \%$ lived with a single parent and $27 \%$ lived with other relatives. 
Table 4

Distribution of sexual intercourse according to participants' characteristics.

\begin{tabular}{|c|c|c|c|}
\hline \multirow[t]{2}{*}{ Variable } & \multicolumn{2}{|c|}{ Ever had sexual intercourse } & \multirow[t]{2}{*}{ Chi square( $P$-Value) } \\
\hline & Yes & No & \\
\hline Age (Years) & & & $104.55(<0.0001)$ \\
\hline $10-14$ & $97(11.84)$ & 721(88.16) & \\
\hline $15-19$ & 162(37.57) & $246(62.43)$ & \\
\hline Sex & & & $82.72(<0.0001)$ \\
\hline Male & $179(32.15)$ & $369(67.85)$ & \\
\hline Female & $80(10.92)$ & $598(89.08)$ & \\
\hline Ever drink alcohol & & & $71.04(<0.0001)$ \\
\hline Yes & $46(59.73)$ & $30(40.23)$ & \\
\hline No & 213(17.96) & $937(82.04)$ & \\
\hline Schooling status & & & $154.93(<0.0001)$ \\
\hline In school & $108(12.47)$ & 790(87.53) & \\
\hline Out of school & $151(46.69)$ & 177(53.31) & \\
\hline Family structure & & & $6.13(0.0465)$ \\
\hline Both parents & $144(19.12)$ & $609(80.88)$ & \\
\hline Single parent & $54(22.13)$ & 190(77.87) & \\
\hline Other & $61(26.64)$ & 168(73.36) & \\
\hline Bullying Victimization & & & 7.73(0.0054) \\
\hline Yes & $74(26.47)$ & 198(73.53) & \\
\hline No & $185(18.63)$ & 769(81.37) & \\
\hline Psychosocial distress indicator & & & $26.04(<0.0001)$ \\
\hline Not distressed & 195(17.94) & $851(82.06)$ & \\
\hline Distressed & $64(34.95)$ & 116(65.05) & \\
\hline Exposed to sexually explicit materials & & & $193.76(<0.0001)$ \\
\hline Yes & $163(46.21)$ & 182(53.79) & \\
\hline No & $96(10.18)$ & 785(89.82) & \\
\hline
\end{tabular}




\section{Factors associated with sexual intercourse among adolescents aged 10-19 years in Dodoma}

The results of the logistic regression analyses are printed in Table 5. In unadjusted analyses, sexual intercourse was associated with psychosocial distress and exposure to sexually explicit materials. All other factors that were included in the analysis were significantly associated with sexual intercourse. The results of bivariate analyses showed that being psychosocially distressed, exposed to sexually explicit materials, older age, male, alcohol use, being out of school and being bullied were positively associated with having sexual intercourse. While living with both biological parents were inversely associated with sexual intercourse. In multivariable regression analysis, psychosocial distress and exposure to sexually explicit material were still associated with sexual intercourse. Among adjusted variables, participants' age, sex, alcohol use, and schooling status were revealed to be significantly associated with sexual intercourse. However, family structure $(p=0.1036)$ and bullying victimization were no longer significant $(p=0.9193)$. Adolescents exposed to sexually explicit materials ( $A O R=4.26, p<0.0001)$ had greater odds of being involved in sexual intercourse than those who were not exposed. Likewise, psychosocially distressed participants were at higher risk of having sexual contacts than those who were not distressed $(A O R=1.61, p<0.0001)$. Adolescents aged 15-19 years had significantly greater odds of being engaged in sexual intercourse in comparison to those aged $10-14$ years $(A O R=2.80, p<0.0001)$. Similarly, the adjusted odds of having sexual intercourse among male adolescents was 2 times that of female counterparts $(A O R=2.44, p<0.0001)$. Alcohol users $(A O R=2.01, p<0.0001)$ were significantly at high risk of being involved in sexual intercourse than non-alcohol users. Besides, the adolescents who were out of school $(A O R=3.22, p<0.0001)$ were significantly more prevalent in sexual intercourse than inschool adolescents.

\section{Table 5}

Results of logistic regression analysis for factors associated with sexual intercourse Among adolescents in Dodoma-Tanzania 


\begin{tabular}{|c|c|c|c|c|}
\hline \multirow[b]{2}{*}{ Variable } & \multicolumn{2}{|c|}{ Unadjusted Analysis } & \multicolumn{2}{|l|}{ Adjusted Analysis } \\
\hline & $\mathrm{OR}(95 \% \mathrm{Cl})$ & P-Value & AOR $(95 \% \mathrm{Cl})$ & P-Value \\
\hline \multicolumn{5}{|l|}{ Age (Years) } \\
\hline $10-14$ & 1 & & 1 & \\
\hline $15-19$ & $4.48[3.94-5.11]$ & $<0.0001$ & $2.80[2.40-3.27]$ & $<0.0001$ \\
\hline \multicolumn{5}{|l|}{ Sex } \\
\hline Male & $3.87[3.38-4.42]$ & $<0.0001$ & $2.44[2.08-2.87]$ & $<0.0001$ \\
\hline Female & 1 & & 1 & \\
\hline \multicolumn{5}{|l|}{ Alcohol use } \\
\hline Yes & $6.77[5.42-8.46]$ & $<0.0001$ & $2.10[1.61-2.74]$ & $<0.0001$ \\
\hline No & 1 & & 1 & \\
\hline \multicolumn{5}{|l|}{ Schooling status } \\
\hline In school & 1 & & 1 & \\
\hline Out of school & $6.14[5.37-7.04]$ & $<0.0001$ & $3.22[2.74-3.78]$ & $<0.0001$ \\
\hline Family structure & & 0.0009 & & 0.1036 \\
\hline Both parents & 1 & & 1 & \\
\hline Single parent & $1.21[1.03,1.42]$ & 0.0183 & $1.05[0.86,1.27]$ & 0.6496 \\
\hline Other & $1.32[1.13,1.54]$ & 0.0006 & $1.23[1.02,1.49]$ & 0.0335 \\
\hline \multicolumn{5}{|c|}{ Bullying Victimization } \\
\hline Yes & $1.57[1.37-1.81]$ & $<0.0001$ & $0.99[0.83,1.18]$ & 0.9193 \\
\hline No & 1 & & 1 & \\
\hline \multicolumn{5}{|c|}{ Psychosocial distress indicator } \\
\hline Not distressed & 1 & & 1 & \\
\hline Distressed & $2.46[2.11-2.87]$ & & $1.61[1.32,1.96]$ & $<0.0001$ \\
\hline \multicolumn{5}{|c|}{ Exposed to sexually explicit materials } \\
\hline Yes & $7.55[6.62-8.68]$ & $<0.0001$ & $4.26[3.65-4.97]$ & $<0.0001$ \\
\hline No & 1 & & 1 & \\
\hline
\end{tabular}

Discussion 
The findings of this study inform of the magnitude of the adolescents' involvement in sexual intercourse as well as its association with psychosocial distress and exposure to sexually explicit materials in Dodoma-Tanzania. Accordingly, $20.38 \%$ of respondents had experienced sexual intercourse in a lifetime. In our study, the occurrence of sexual intercourse was lower than the reported prevalence (26.5\%) among the student adolescents in Goiania in the state of Goias, Brazil[10] and that of adolescents in Ethiopia [11, 27]. However, our estimate was higher than the reported prevalence (14.9\%) among adolescents in Kenya [3]. In our study, adolescents with psychosocial distress were likely to have sexual contacts. Similar findings were reported by Peltzer and Pengpid in Thailand [20]. The findings of the National Longitudinal Survey of Adolescent Health showed that sexually active adolescents were significantly more likely to be depressed and attempt suicide compared to those who had not had sex[21]. The study of adolescent sexual behavior in Sub-Saharan African countries by Randy and Cougar also found that the risk of having sexual intercourse was significantly higher when adolescents experienced psychosocial distress [22]. Given the cross-sectional design of our study and the association between adolescent sexuality and psychosocial distress, this association is subjected to different interpretations. One of the interpretations is that psychosocially distressed young people turn to sexual intercourse as a means to run away from distressful feelings, such as loneliness, anxiety or worried sadness, and suicide attempt. Also, from the perspective of the cross-sectional study, the opposite direction of effect is similarly possible in that sexual intercourse among adolescents could lead to increased psychosocial distress. Another explanation is that sexual intercourse and psychosocial distress are both related to third variables (confounders) and the relationship can be explained by these confounders. In our study, we were able to statistically rule out sex, age, school status, alcohol use, family structure, bullying victimization and exposure to sexually explicit materials as confounders as they were statistically adjusted in analyses. Due to this dilemma, more prospective studies are required in this area that can identify the causal direction of effect and factors that influence adolescents' sexuality[28, 29].

Our findings also revealed that adolescents exposed to sexually explicit materials were significantly more likely to be the risk of engaging in sexual intercourse. These findings are supported by those of previous studies[17, 18], signifying that exposure to sex in media messages is a risk factor for early sexual progression. These results are also consistent with findings of the research conducted in Nigeria[30], indicating that those who used the Internet or accessed sexually explicit materials being more likely to be sexually active as compared to non-exposed counterparts. The study showed that adolescents who ever engaged in sexual intercourse were also more likely to have used alcohol. The finding that alcohol use was associated with sexual intercourse is consistent with that reported in Kenya and Thailand among school-going adolescents $[3,20]$. Randy and Cougar also reported that the use of alcohol among SubSaharan African adolescents was associated with having sexual intercourse[22]. A similar association has also been reported among the GSHS in six African countries [22, 31].

As demonstrated in other studies conducted with adolescents [32-34], this study found that more males than females reported being engaged in sexual intercourse. A similar finding had also been reported by Peltzer and Pengpid in Thailand[20]. These differences in sexual relations between genders could be due to the behaviors of adolescent males. For example, more males (58\%) than females (20\%) reported 
having multiple sexual partners, and even though the use of condom is strongly associated with the reduction of several STIs[35]. In our sample used, $76 \%$ of males and $61 \%$ of females did not use condom as a contraceptive method during the last time they had sexual intercourse. It is also likely that females' greater perception of shame and guilt with sex can clarify the differences in the prevalence of sexual intercourse among females versus males. The previous study has reported that, though shame and guilt protected males and females equally from having sexual intercourse, females were much more likely to perceive shame and guilt with sex than males[34].

School connectedness is among the defensive factors for adolescents to be involved in sexual intercourse. This study is in favor of the association which is in school adolescents found to be less likely to be engaged in sexual intercourse than adolescents who were out of school. The lower prevalence of sexual intercourse among in-school adolescents has the explanation that being in school creates chances to engage with various health promotion programs, like school-based Voluntary Counseling and Testing (VCT) service programs and school clubs which allow the adolescents to obtain more new information and knowledge related to the service.

\section{Limitations And Strength Of The Study}

Some limitations are pointed out in this study. The study is limited by the design of the study in that the cross-sectional design does not demonstrate the causality of the association between the supposed exposure factors and sexual intercourse. For example, it is difficult to establish whether exposure to sexually explicit material contributes to engagement in sexual contacts or whether those involved in sexual intercourse tend to seek out sexually explicit materials. Prospective studies are required to follow adolescent sexuality and associated factors. Second, the outcome measure was self-reported. This is limited by the fact that sexuality is a sensitive topic, and since the study relied on self-reports, social desirability bias could limit the findings of this study since participants are likely to under-report on their sexual practices. However, this potential source of bias was minimized by assuring that the participants had the confidence in their privacy and confidentiality in data handling. Despite the limitations, several factors demonstrate the strength of the study. First, the sample size was relatively large. This ensured the power to note any difference among individuals of different groups. Also, the Dodoma adolescents study enrolled both adolescents who are in school and out of school. This is a representative of all adolescents aged 10-19 years in Dodoma as the occurrence of sexual behavior may differ between the two groups. Thus, the findings do not only reflect the school attending adolescents but also the adolescents who have dropped out of school or not be able to attend school.

\section{Conclusions}

Sexual contacts by younger adolescents is associated with the increase in the risk of multiple partners, pelvic inflammatory disease, unintended pregnancy, HIV and other sexually transmitted diseases [4-8]. This study gives evidence that sexual intercourse among adolescents is positively associated with 
psychosocial distress and exposure to sexually explicit materials. Therefore, the efforts to control psychosocial distress and exposure to sexually explicit materials may have an impact on the magnitude of sexual intercourse among adolescents.

\section{Abbreviations}

HDSS: Health and Demographic Surveillance System, THIS: Tanzania HIV Impact Survey, GSHS: Global School-based Student Health Survey, SEM: Sexually explicit material, UDOM: University of Dodoma, AAPH: Africa Academy for Public Health, ODK: Open Data Kit, AOR: Adjusted odds ratio, OR: Unadjusted odds ratio.

\section{Declarations}

\section{Ethics approval and consent to participate}

Informed written consent of participation was sought from both parents and each adolescent before measurements or interviews. The ethical clearance was sought from the ethical review board of the University of Dodoma. To ensure adherence to ethics and safety, confidentiality was maintained at all times. An informed consent form that included all elements of informed consent was translated into Kiswahili, a language that is well understood by the participants of the study.

\section{Consent for publication}

Not applicable

\section{Availability of data and materials}

The datasets used during the current study are available from the corresponding author on reasonable request.

Competing interests: The author declares that he has no competing interests.

\section{Funding}

The Dodoma Health and Demographic Surveillance System (HDSS) adolescents nested Survey was funded by Africa Academy for Public Health (AAPH). The funds were provided for study design and data collection. No funds provided for analysis, interpretation of data and in writing the manuscript.

\section{Authors' contributions}

AH substantial contributes to the conception of the work, analysis, and interpretation of the data. $A H, H D$, Al and AM drafted the initial manuscript. MS, JC, SV and WF revised the manuscript for important intellectual content. AH and HD wrote the final manuscript. All authors read and approved the final version to be published. 


\section{Acknowledgments}

I would like to acknowledge the Department of Global Health and Population at Harvard T.H. Chan School of Public Health for funding the data collection process. The author would also like to thank AAPH, the University of Dodoma, and the Dodoma HDSS team, without forgetting the research assistants involved in the study. i My thanks are also to the Dodoma Region and Chamwino District management for permitting to conduct the study in the respective sites.

\section{Authors' Information}

${ }^{1}$ Department of Statistics, School of Mathematical Science, Collage of Natural and Mathematical Sciences, the University of Dodoma, Tanzania

${ }^{2}$ Department of Computer Sciences, Collage of Informatics and Visual Education, The University of Dodoma, Tanzania

${ }^{3}$ Department of Educational Management and Policy Studies, the University of Dodoma, Tanzania

${ }^{4}$ Dodoma Regional Hospital, Tanzania

${ }^{5}$ Africa Academy for Public Health, Tanzania

${ }^{6}$ Department of Global Health and Population, Harvard T.H. Chan School of Public Health, United States

${ }^{7}$ Department of Chemistry, the University of Dodoma, Tanzania

\section{References}

1. UNAIDS. Number of people living with HIV. 2016 16/04/2018]; Available from: http://aidsinfo.unaids.org/.

2. National Bureau of Statistics-NBS/Tanzania and. Statistician-OCGS/Zanzibar OoCG. 2016-17 Tanzania HIV Impact Survey (THIS): Summary Sheet - Preliminary Findings. 2017, NBS: Dar es Salaam, Tanzania.

3. Rudatsikira E, et al. Prevalence of sexual intercourse among school-going adolescents in Coast Province, Kenya. Tanzania Journal of Health Research. 2007;9(3):159-65.

4. Edgardh K. Sexual behaviour and early coitarche in a national sample of 17 year old Swedish girls. Sex Transm Infect. 2000;76(2):98-102.

5. Suss AL, et al. Risk Factors for Pelvic Inflammatory Disease in Inner-City Adolescents. Sexually transmitted diseases. 2000;27(5):289-91.

6. Coker AL, et al. Correlates and consequences of early initiation of sexual intercourse. J Sch Health. 1994;64(9):372-7. 
7. O'Donnell L, O'Donnell CR, Stueve A, Early sexual initiation and subsequent sex-related risks among urban minority youth: The reach for health study. Family planning perspectives, 2001: p. 268-275.

8. Kaestle $\mathrm{CE}$, et al. Young age at first sexual intercourse and sexually transmitted infections in adolescents and young adults. Am J Epidemiol. 2005;161(8):774-80.

9. Bongaarts J. Late marriage and the HIV epidemic in sub-Saharan Africa. Popul Stud. 2007;61(1):7383.

10. Sasaki RSA, et al., Prevalence of sexual intercourse and associated factors among adolescents attending schools in Goiânia in the state of Goiás, Brazil. Ciencia \& saude coletiva, 2015. 20(1): p. 95-104.

11. Hurissa B, Tebeje B, Megersa H, Prevalence of Pre-marital Sexual Practices and Associated Factors among Jimma Teacher Training College Students in Jimma Town, south west Shoa Zone, Oromiya Region, Ethiopia-2013. J Women's Health Care, 2014. 4(221): p. 2167-0420.1000221.

12. Ministry of Health. Tanzania Mainland Global School-based Student Health Survey (GSHS) report. 2017.

13. Ueno K. Sexual orientation and psychological distress in adolescence: Examining interpersonal stressors and social support processes. Social Psychology Quarterly. 2005;68(3):258-77.

14. Arulogun OS, Ogbu IA, Dipeolu IO. Influence of internet exposure on sexual behaviour of young persons in an urban district of Southwest Nigeria. The Pan African Medical Journal, 2016. 25.

15. Peter J, Valkenburg PM. Adolescents' exposure to sexually explicit material on the Internet. Communication Research. 2006;33(2):178-204.

16. Habesha T, Aderaw Z, Lakew S. Assessment of exposure to sexually explicit materials and factors associated with exposure among preparatory school youths in Hawassa City, Southern Ethiopia: a cross-sectional institution based survey. Reproductive health. 2015;12(1):86.

17. Brown JD, et al. Sexy media matter: exposure to sexual content in music, movies, television, and magazines predicts black and white adolescents' sexual behavior. Pediatrics. 2006;117(4):1018-27.

18. Collins RL, et al. Watching sex on television predicts adolescent initiation of sexual behavior. PEDIATRICS-SPRINGFIELD-. 2004;114(3):843-3.

19. Hoare $\mathrm{E}$, et al. Depression, psychological distress and Internet use among community-based Australian adolescents: a cross-sectional study. BMC Public Health. 2017;17(1):365.

20. Peltzer K, Pengpid S. Prevalence and social correlates of sexual intercourse among school-going adolescents in Thailand. The Scientific World Journal. 2011;11:1812-20.

21. Rector RE, Johnson KA, Noyes LR. Sexually Active Teenagers Are More Likely To Be Depressed and To Attempt Suicide. A Report of the Heritage Center for Data Analysis. 2003.

22. Page RM, Hall CP. Psychosocial Distress and Alcohol Use as Factors in Adolescent Sexual Behavior Among Sub-Saharan African Adolescents. J Sch Health. 2009;79(8):369-79.

23. Tanzania National Bureau of Statistics (NBS). The 2012 Population and Housing Census, Age and Sex Distribution Report, Dar es Salaam, Tanzania. 2012. 
24. Asangansi I, Braa K. Improving the routine HMIS in Nigeria through mobile technology for community data collection. JHIDC, 2013. 7(1).

25. Homan T, et al. Innovative tools and OpenHDS for health and demographic surveillance on Rusinga Island, Kenya. BMC Res Notes. 2015;8:397.

26. Agresti A, Categorical Data Analysis. 2nd Edition ed. 2002, New York: John Wiley \&Sons.

27. Teferra TB, Erena AN, Kebede A. Prevalence of premarital sexual practice and associated factors among undergraduate health science students of Madawalabu University, Bale Goba, South East Ethiopia: institution based cross sectional study. Pan African medical journal, 2015. 20(1).

28. King SM, lacono WG, McGue M. Childhood externalizing and internalizing psychopathology in the prediction of early substance use. Addiction. 2004;99(12):1548-59.

29. Devine D, Long P, Forehand R. A prospective study of adolescent sexual activity: Description, correlates, and predictors. Advances in Behaviour Research Therapy. 1993;15(3):185-209.

30. Asekun-Olarinmoye OS, et al. effect of mass media and internet on sexual behavior of undergraduates in Osogbo metropolis, southwestern nigeria. Adolescent health medicine therapeutics. 2014;5:15.

31. Chinsembu KC, Kas CD, Shimwooshili-Shaimemanya CN. Prevalence, distribution and behavioural determinants of coital activity among High School students in Namibia: A cross-sectional study. Journal of Public Health Epidemiology. 2011;3(7):308-16.

32. Santelli JS, et al. Initiation of sexual intercourse among middle school adolescents: The influence of psychosocial factors. Journal of adolescent health. 2004;34(3):200-8.

33. Miller KE, et al., Athletic participation and sexual behavior in adolescents: The different worlds of boys and girls. Journal of Health and Social Behavior, 1998: p. 108-123.

34. Cuffee JJ, Hallfors DD, Waller MW. Racial and gender differences in adolescent sexual attitudes and longitudinal associations with coital debut. Journal of adolescent health. 2007;41(1):19-26.

35. Warner $L$, et al. Condom use and risk of gonorrhea and Chlamydia: a systematic review of design and measurement factors assessed in epidemiologic studies. Sexually transmitted diseases. 2006;33(1):36-51.

\section{Supplementary Files}

This is a list of supplementary files associated with this preprint. Click to download.

- STROBEcrosssectionalchecklist.docx 